\title{
Analysis on Transient Temperature Field of the Rod Fastening Rotor Based on Fractal Contact Theory
}

\author{
Yiping $\mathrm{Li}^{*}$ \\ School of Chemical and Environmental Engineering Shanghai Institute of Technology, Shanghai 201418, China \\ ${ }^{*}$ Corresponding author
}

\begin{abstract}
When the disks of the rod fastening rotor were contacted with each other, the contact thermal resistance between the contact surfaces would play a critical role in heat transfer and the distribution of temperature field. On the basis of the surface fractal characteristics, combining Mandelbrot - Tian (M - T) fractal network model and the classical conduction theory, the Cantor set, which was not dependent on the observation scale, was chosen to obtain the relationship between the pressure and the heat transfer coefficient of contact surfaces. The rotor transient temperature field distribution was obtained through determining the contact thermal resistance. It was found that the thermal conductivity caused by the pre-tightening force had a little influence on the transient temperature field. Therefore, when the rotor dynamic characteristics were analyzed, the influence of the transient temperature field could be ignored.
\end{abstract}

Keywords-transient temperature field; contact thermal resistance; rod fastening rotor; fractal contact theory

\section{INTRODUCTION}

Rod fastening rotor was used by many heavy-duty gas turbine, which was consist of many discs compacted by a single central rod bolts or circumferential rod bolts. The contact interface between discs was either plane or terminal face tooth. The contact thermal resistance between the contact interfaces of discs would affect the rotor temperature distribution and impacted on the rotor dynamics[1]. Fractal theory described the rough surface morphology by using the fractal dimension which was nothing to do with the scale of roughness parameters. The heat conduction model was set up through the rough self-affine fractal surface, which was expected to further reveal the physical nature of heat conduction. In this paper, the heat transfer coefficient under different contact pressure was obtained by using the fractal Cantor set theory. The transient temperature field, which was affected by the contact thermal resistance, was studied.

\section{CONTACT THERMAl RESISTANCE AND HEAT TRANSFER COEFFICIENT}

When two metal surfaces were contacted with other, the nominal surfaces seemed to contact entirely, but the real contact parts were dispersed convex body. The presence of these convex bodies would make contact plane not complete. Bowden[2] pointed out that under the condition of pressure up to $10 \mathrm{MPa}$, the actual contact area was only $1 \% \sim 2 \%$ of the nominal contact area, which generated the contact thermal resistance $\mathrm{R}$, expression was as follows:

$$
R=\frac{\Delta T}{q} .
$$

Where $\Delta \mathrm{T}$ was the temperature difference between the two contact surface, its dimension was ${ }^{\circ} \mathrm{C}$; q was average heat flux density of the contact surface, its dimension was W/m2. Contact element in ANSYS could simulate the contact thermal resistance between the surfaces. To take into account the conductive heat transfer between contact and target surfaces, it was need to specify the thermal contact conductance coefficient which was real constant TCC. The conductive heat transfer between two contact surfaces was defined by:

$$
q=T C C \times \Delta T
$$

Where q was the heat flux per area; TCC was the thermal contact conductance coefficient, having dimensions of $\mathrm{W} / \mathrm{m} 2 \cdot \mathrm{K}$; $\Delta \mathrm{T}$ was the temperature difference between the two contact surfaces. TCC was a function of temperature, pressure, time and location. After the thermal contact conductance coefficient between plates were obtained by fractal Cantor set elastic-plastic deformation model, the model of the finite element calculation and analysis of transient temperature field could be established.

\section{Fractal THEORY BASED ON CANTOR SET}

\section{A. Morphology Characteristics Based on Cantor Set}

By the conclusion of the literature [3]: The cantor set of contact surface and the surface generation process was: from down to up, each step after segmentation, the length of the line segment of the layer was $1 / f_{r}\left(f_{r}>1\right)$ of pre-layer. Vertically, each fractal depth was $1 / f_{z}\left(f_{z}>1\right)$ of pre-depth. $f_{r}$ was level reduction ratio, $f_{z}$ was vertical reduction ratio, $s$ was each layer of the fractal repeat part. Based on the literature [3], the derivation of self affine fractal Cantor set surface profile fractal dimension was as follows: 


$$
D=1-\frac{\ln f_{z}}{\ln \left(s f_{r}\right)}+\frac{\ln s}{\ln \left(s f_{r}\right)} \quad 1<D<2 .
$$

Specific contact surface could be described by a particular Cantor set parameters s, fr and fz. The surface roughness Ra (its dimension was um) could be measured, according to the experiments of literature [4]. The fractal roughness parameter $\mathrm{G}$ (its dimension was $\mu \mathrm{m}$ ) and fractal dimension $\mathrm{D}$ of Cantor set were obtained through the surface roughness by approximate conversion formula:

$$
\begin{aligned}
& D=1.2996 / R_{a}^{0.2178} \\
& G=10^{8.2594} / R_{a}^{0.2183} .
\end{aligned}
$$

The measurement sampling contour length, which corresponding to Cantor set morphology parameters, were substituted by its related length[5]:

$$
l_{0}=\left[(4-2 D) / G^{2 D-2}\right]^{1 /(4-2 D)} .
$$

The level reduction ratio and the vertical reduction ratio could be achieved by the relation of Warren[5] normal displacement $u$ and contact area (or cross-sectional area) Ar:

$$
A_{r}=\frac{l_{0}^{2}}{k \varphi}\left(\frac{R_{q}-u}{f_{z} h_{0}}\right)^{k} \quad k=\frac{\ln f_{r}^{2}}{\ln f_{z}}, \quad \varphi=\frac{f_{z}-1}{f_{r}^{2}-1} .
$$

Where h0 was 2 times as each contact surface root mean square roughness $\mathrm{Rq}$. The cross-sectional area of the rough surface contour Ar1 and Ar2 could be obtained with different height (Rq-u1) and (Rq-u2) intercept and equation (7). The reduction ratio fr and fz could be obtained by solving nonlinear equations simultaneously, and $\mathrm{s}$ could be obtained by the formula (3).

\section{B. Thermal Resistance Model}

According to the literature [3], the real contact state could be equivalent to the contact state between the Cantor set fractal rough surface with elastic-plastic deformation and the ideal smooth rigid half infinite solid surface. Under the load F, the some materials of contact surface would begin to produce plastic deformation and flow into the groove between two convex bodies until the end of (nc-1) generation. So for a given normal load, the rough surface in every generation of convex bodies could be divided into two categories: 1) the range of [nc, $\infty$ ], generation of the plastic deformation; 2) the range of [0, nc-1], generation of the elastic deformation. The value of Critical generation nc was:

$$
n_{c}=\operatorname{trnu}\left[\frac{\ln \xi}{\ln \left(1 / f_{r}^{2}\right)}\right] \quad \xi=\frac{F}{\sigma_{y} \cdot l_{0}^{2}} .
$$

Supposing, when a given normal load $\mathrm{F}$ was applied on the surface of cantor set, plastic flow of the convex body of [nc, $\infty$ ] generation would occur and flow completely into the adjacent clearance gap. Based on the plastic deformation model of Warren t. L[5], the plastic displacement of nc generation could be obtained. The height increment of (nc-1) generation could be calculated at the case of volume conservation. Based on recursive generation process of fractal theory of contact surface, the total thermal resistance of the contact surface were consist of convex body contraction thermal resistance and heat conduction thermal resistance, the total contact thermal resistance was given by:

$$
R_{t, 0}=\frac{\sum_{i=1}^{n_{c}-1} s^{2 i}\left(R_{b,\left(n_{c}-1-i\right)}+R_{c,\left(n_{c}-1-i\right)}\right)}{s^{2 n_{c}}}, 0 \leq i \leq n_{c}-1 .
$$

Where $\mathrm{Rb}$ was thermal resistance of the heat conduction of the convex body, Rc was contraction thermal resistance of the convex body.

\section{Transient HeAt Transfer ANALYSIS OF THE TESTING ROTOR}

\section{A. Rotor Disc Model and Contact Heat Transfer Coefficient}

The material of the testing rotor disc was steel 45, its structure size was shown in Figure I.

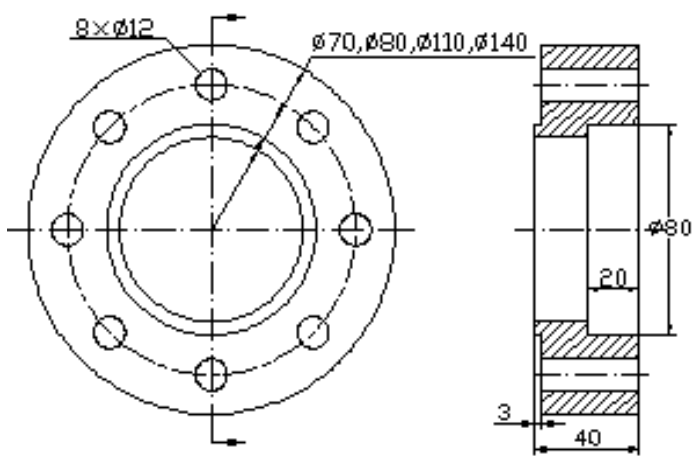

FIGURE I. THE STRUCTURE OF TESTING ROTOR DISC

In this paper, based on the size of the testing rotor disc, the 3D model and finite element model were established through ANSYS APDL programming. Because the structure of the rotor was symmetrical, 1/8 of testing rotor disc was established by using SOLID 90 elements for swept meshing. A total of 21522 elements and 91615 nodes were generated. Two-dimensional TARGE 170 and CONTA 174 were selected to simulate contact, testing rotor disc assembly and grid diagram were shown in Figure II. 


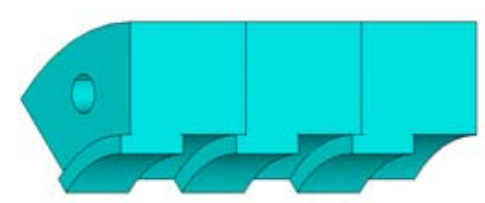

A) 1/8 ROTOR ASSEMBLY

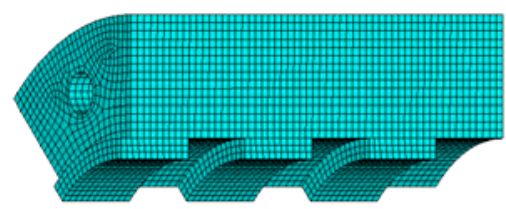

B) GRID OF 1/8 ROTOR ASSEMBLY

FIGURE II. 1/8 TESTING ROTOR DISC ASSEMBLY AND ITS GRID DRAWING

The section area Ar of a single rod was $7.85 \times 10-5 \mathrm{~m} 2$, yield strength $\sigma$ s of the steel 45 was $500 \mathrm{MPa}$, the safety factor could be set as 2 , allowable stress $[\sigma]=\sigma \mathrm{s} / 2=250 \mathrm{MPa}$. In order to prevent the rod failure in the experiments, the pre-tightening load $\mathrm{FN}<[\sigma] \times \mathrm{Ar}=19.6 \mathrm{kN}$. The scope of pre-tightening force could be appropriately expanded by calculation of the theoretical vale. The contact pressure under pre-tightening force $30 \mathrm{kN}$ could be calculated:

$$
P=\frac{F}{A_{w}}=\frac{30000 N}{1.21 \times 10^{-3} m^{2}}=24.8 \mathrm{MP}_{\mathrm{a}}
$$

Where, Aw was the disc area of $1 / 8$ testing rotor. According to the theoretical analysis in second section, Cantor set elastic-plastic deformation and the calculation program of contact thermal resistance could be obtained based on Matlab. The fractal parameters of the contact surface could be obtained by the surface profiler. The parameters in table 1 were used in the Matlab program to calculate thermal resistance.

TABLE I. THE SURFACE FRACTAL PARAMETERS AND MATERIAL PARAMETERS OF STEEL 45

\begin{tabular}{|c|c|c|c|c|c|}
\hline \begin{tabular}{c|} 
Roug \\
hness \\
$R_{\mathrm{a}} / \mu$ \\
m
\end{tabular} & $\begin{array}{c}\text { Level } \\
\text { reduction } \\
\text { ratio } \\
f_{\mathrm{r}}\end{array}$ & $\begin{array}{c}\text { Vertical } \\
\text { reduction } \\
\text { ratio } \\
f_{\mathrm{z}}\end{array}$ & $\begin{array}{c}\text { Thermal } \\
\text { conductivit } \\
\mathbf{y} \\
\mathrm{k} / \mathrm{W} / \mathrm{m} \cdot \mathrm{K}\end{array}$ & $\begin{array}{c}\text { Yield } \\
\text { strengt } \\
\text { h } \\
\sigma_{\mathrm{y}} / \mathbf{M P}_{\mathrm{a}}\end{array}$ & $\begin{array}{c}\text { Elastic } \\
\text { modulus } \\
E / M_{a}\end{array}$ \\
\hline 0.8 & 1.26 & 1.21 & 44 & 500 & $2.1 \times 10^{5}$ \\
\hline
\end{tabular}

According to the fractal parameters of the rough surface, the discrete relationship between the contact pressure and the heat transfer coefficient of the contact surface of a rod fastening rotor under $30 \mathrm{kN}$ load could be obtained by the Matlab program, and furthermore, the linear relationship between the contact pressure and the heat transfer coefficient of the contact surface could be fitted. Based on the output image of the contact stress, the linear relationship between contact stress and the heat transfer coefficient of the contact surface was shown in Figure III.

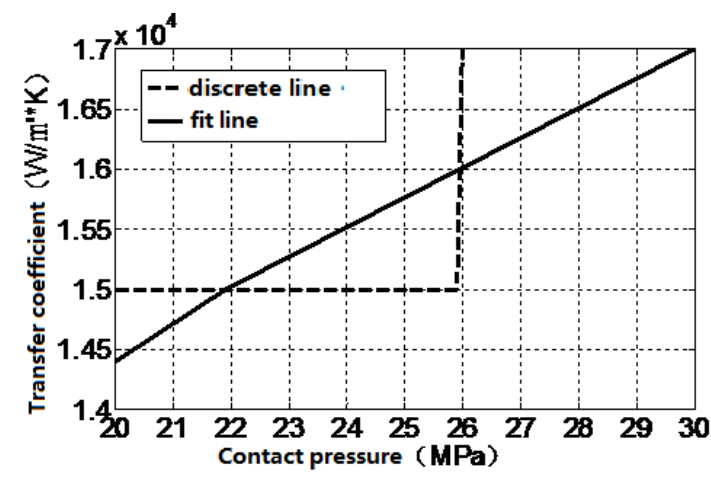

FIGURE III. CONTACT PRESSURE AND THE HEAT TRANSFER COEFFICIENT OF THE CONTACT SURFACE

According to Figure III, when the contact pressure was 24.8 $\mathrm{MPa}$, the heat transfer coefficient of the contact surface was $15.6 \mathrm{~kW} / \mathrm{m} 2 . \mathrm{K}$. Therefore, the heat transfer coefficient of the contact surface under any contact pressure could be obtained.

\section{B. Calculation of Transient Heat Transfer}

In order to study the influence of heat transfer coefficient of the different contact surface on the transient heat transfer process, a simple example was designed. The contact area of the disks was set up contact pair; the heat transfer coefficient of the interface was $15.6 \mathrm{~kW} / \mathrm{m} 2 . \mathrm{K}$. Supposing the rotor surface was insulation and material coefficient of thermal conductivity was $44 \mathrm{~kW} / \mathrm{m} 2 . \mathrm{K}$. The material density was $7850 \mathrm{~kg} / \mathrm{m} 3$, specific heat capacity was $560 \mathrm{~J} / \mathrm{kg} . \mathrm{K}$. The initial temperature for the left disc was $500^{\circ} \mathrm{C}$, the initial temperature for other two was $25^{\circ} \mathrm{C}$, shown in Figure IV.

In order to execute transient analysis, the calculation time was $600 \mathrm{~s}$. The temperature distribution at $100 \mathrm{~s}$ was shown in Figure V. The temperature distribution, which was shown by color, changed rapidly in contact surface, which meant that there was a larger temperature difference between the contact interfaces.

According to the same way, when rod pre-tightening force was $25,20,15,10$ and $5 \mathrm{kN}$ respectively, the heat transfer coefficient of the interface was 14.6, 13.2, 12.5, 10.1 and $8.3 \mathrm{~kW} / \mathrm{m} 2 \cdot \mathrm{K}$ respectively. Settings the heat transfer coefficient of the interface respectively, the temperature of node 23646 on the third disc of the rotor model was extracted to draw curve with time, which were used to simulate respectively working conditions of rod pre-tightening force of 30, 25, 20, 15, 10 and $5 \mathrm{kN}$, the result was shown in Figure VI.

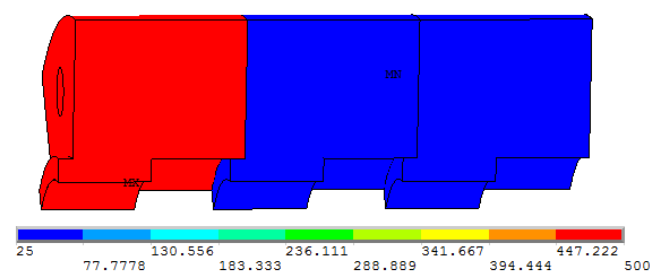

FIGURE IV. THE INITIAL CONDITIONS OF THE ROTOR DISC FOR TRANSIENT ANALYSIS 


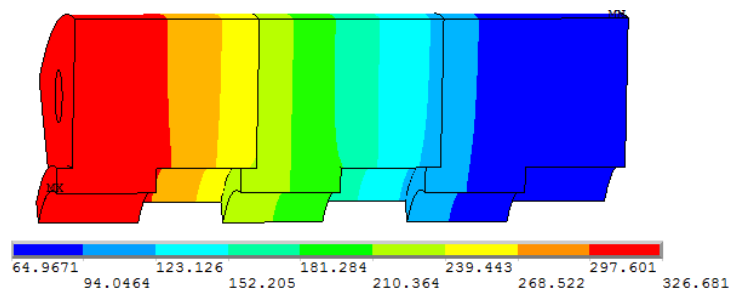

FIGURE V. TEMPERATURE DISTRIBUTION IN TESTING ROTOR AT $100 \mathrm{~S}$

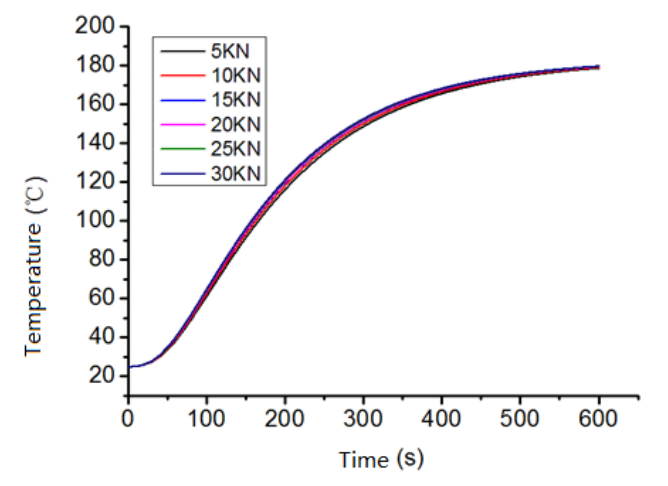

FIGURE VI. TEMPERATURE CHANGES OF NODE 23646

When the pre-tightening force was $20 \mathrm{kN}$, a series of nodes in axial direction of the rotor discs were selected at the time 20, 60 and $100 \mathrm{~s}$, which revealed the temperature field distribution, and could be used to compare with the conditions without thermal resistance. The temperature distribution was shown in Figure VII.

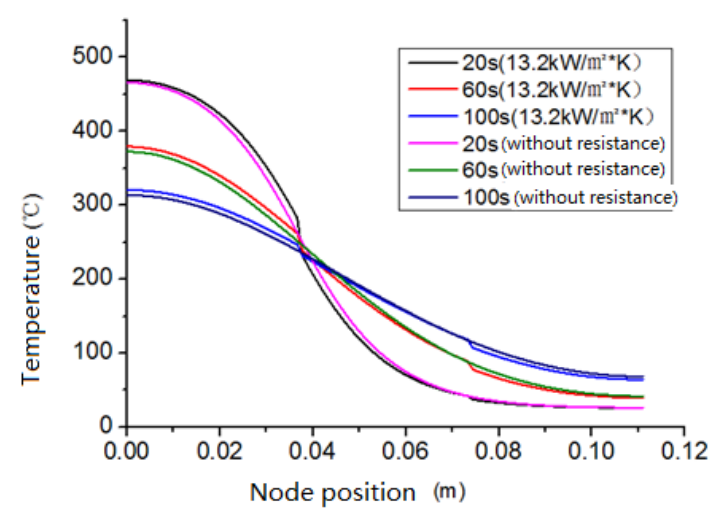

FIGURE VII. THE AXIS TEMPERATURE DISTRIBUTION UNDER 20KN AND WITHOUT THERMAL RESISTANCE

The simulation results shown that, when the pre-tightening force increased, the heat transfer distance of the contact interface decreased, and at the same time, the real contact area increased, which resulted in the increase of the heat transfer coefficient of the contact surface between the discs. Because the heat transfer process was prevented by contact thermal resistance, and temperature field distribution was also influenced, the influence of thermal contact resistance cannot be ignored.

\section{SUMMARY}

Analysis on the transient heat transfer of testing rotor model was done by using ANSYS. When the influence of the contact pressure on the contact surface heat transfer coefficient was taken into account, the Cantor set of the fractal theory, which was not dependent on the observation scale, was chosen to obtain the relationship between the pressure and the heat transfer coefficient. The change regularity of temperature with time was analyzed under the different pre-tightening force. It was found that the pre-tightening force leaded to the change of contact pressure, and further leaded to the change of the heat transfer coefficient of the contact surface. Therefore, the transient temperature field distribution was influenced by the pre-tightening force. The distribution of temperature field was also influenced by the contact thermal resistance. The contact thermal resistance model could be used to determine the heat transfer coefficient of the contact surface. The influence of the thermal stress on the transient temperature field could be ignored.

\section{ACKNOWLEDGEMENT}

This project is supported by National Natural Science Foundation of China (Grant No. 51475311).

\section{REFERENCES}

[1] He Peng, Research of the influences of elastic-plastic contact and temperature distribution on tie-bolted fastened rotor dynamics, Jilin: Harbin Institute of Technology, 2013 (in Chinese).

[2] F.P Bowden, D. Tabor, The friction and lubrication of solids, Oxford University Press, London, 1950.

[3] Xu Ruiping. Study on thermal contact resistance of solid interfaces Cantor set based on fractal theory, Shanghuai: Shanghuai Jiaotong University, 2005 (in Chinese).

[4] Tian Hongliang. Dynamic modeling on fixed joint interface virtual material in mechanical structure, Wuhan: Huazhong University of Science and Technology, 2011(in Chinese).

[5] T.L. Warren, D. Krajcinovic, Random Cantor set models for the elastic-perfectly plastic contact of rough surface, Wear. (1996) 1-15.

[6] R. P. Xu, L. Xu, An experimental investigation of thermal contact conductance of stainless steel at low temperatures, Cryogenics. (2005) 694-704.

[7] Fu Shixin, Physical parameters characterization research of mechanical joint interface on thermo-mechanical coupled loads, Wuhan: University of Science and Technology, 2013 (in Chinese).

[8] Gao Yaodong, Zhang Yubao, Ren Xueping, Finite Element Theory and ANSYS Application, Electronics industry press, Beijing, 2016 (in Chinese). 